\title{
Locoregional Management of Inflammatory Breast Cancer
}

\author{
Jennifer L. Baker ${ }^{1} \cdot$ John Hegde $^{2} \cdot$ Carlie K. Thompson $^{1} \cdot$ Minna K. Lee ${ }^{1} \cdot$ Maggie L. DiNome $^{1}$ (D)
}

Accepted: 26 October 2020 / Published online: 18 November 2020

(C) The Author(s) 2020

\begin{abstract}
Purpose of Review Inflammatory breast cancer (IBC) is a biologically aggressive subtype with a high risk for rapid local progression and early distant metastasis. We review the updated data for optimal locoregional management of IBC, including areas of active controversy.

Recent Findings Advancements in tri-modality therapies have improved survival among IBC patients in recent years; however, the risk of locoregional and distant recurrence remains high, particularly in triple-negative IBC. Data to support de-escalation of surgery or radiotherapy is limited, and the recommended treatment approach for non-metastatic IBC remains preoperative systemic therapy (PST), modified radical mastectomy (MRM), and adjuvant radiotherapy in all patients. For patients with de novo metastatic disease, locoregional intervention may be appropriate.

Summary Optimal locoregional management of IBC remains PST followed by MRM and adjuvant radiotherapy. With increasingly effective systemic therapies, research to identify a subset of patients who may benefit from de-escalation of locoregional therapies is warranted.
\end{abstract}

Keywords Inflammatory breast cancer · Locoregional therapy · Inflammatory carcinoma

\section{Introduction}

Inflammatory breast cancer (IBC) is a distinct, biologically aggressive subtype of breast cancer, characterized by rapid disease progression and a propensity for early distant metastases [1]. While rare, it has a high mortality rate; representing only $2-3 \%$ of breast cancers diagnosed annually in the USA, IBC accounts for $8-10 \%$ of breast cancer-related deaths $[1,2]$. Historically, the prognosis of IBC has been dismal, and attempts at local therapy have been futile, with early local failure in most patients and a median overall survival (OS) of only 1.2 years [3-5]. However, advances in systemic therapy, surgery, and radiotherapy have yielded substantial improvements in clinical outcomes, with contemporary series reporting OS

This article is part of the Topical Collection on Local-Regional Evaluation and Therapy

Maggie L. DiNome

mdinome@mednet.ucla.edu

1 Department of Surgery, University of California Los Angeles, 10833 Le Conte Avenue, CHS 72-215, Los Angeles, CA 90095, USA

2 Department of Radiation Oncology, University of California Los Angeles, Los Angeles, CA, USA rates of $55-71 \%$ at $2-5$ years [6-12]. This success largely reflects the rapid evolution of our understanding of breast cancer biology and subsequent treatment. While the trimodality treatment approach for IBC is comparable to that of locally advanced breast cancers (LABC), IBC remains a unique therapeutic challenge. This report highlights key considerations and optimal treatment strategies for current-day management of this biologically distinct breast cancer subtype.

\section{Locoregional Management: Historical Perspective}

In the prechemotherapy era, attempts at locoregional management of IBC were unsuccessful, resulting in a uniformly fatal outcome. In 1943, Haagenson and Stout reported outcomes of 20 cases of IBC treated with radical mastectomy alone with a mean survival of 15.5 months and no patient surviving 5 years [4]. The use of radiotherapy as the sole treatment for IBC was equally ineffective with studies demonstrating early locoregional recurrence (LRR), dismal survival, and a high incidence of radiation-induced complications [3, 13, 14]. With the introduction of adriamycin-based chemotherapy in 
the 1970s, however, 5-year OS rates were noted to increase to $30-40 \%$ [15-17].

Surgery and radiation, in conjunction with systemic therapy, were subsequently recognized as critical components for the treatment of patients with IBC; extent and sequencing of locoregional treatment, however, continued to evolve [18-20]. In a series of 308 IBC patients treated with curative intent in the era of anthracycline-based chemotherapy, local relapse-free survival (LRFS) was improved when mastectomy was performed after chemotherapy, compared to prior to chemotherapy or not at all (10-year LRFS was $62.8 \%$ vs $58.6 \%$ vs $34.4 \%$, respectively) [19]. Among 178 women with IBC treated with preoperative systemic therapy (PST) at MD Anderson Cancer Center from 1974 to 1993 , LRR at 5 years was $16.3 \%$ in patients treated with mastectomy plus radiotherapy, compared to $35.7 \%$ in patients treated with radiotherapy alone [20]. Patients with a partial response to PST were noted to benefit the most from the addition of mastectomy. Importantly, improved local control was associated with improved disease-free, overall, and cause-specific survival [18, $21,22]$.

\section{Locoregional Management: Modern Perspective}

International expert consensus panels and the National Comprehensive Cancer Network (NCCN) currently recommend a tri-modality treatment approach for IBC. This regimen includes PST, a modified radical mastectomy (MRM), and post-mastectomy radiotherapy (PMRT). If there is marginal response or clinical progression on PST, additional systemic therapy and/or preoperative radiotherapy are considered, with further local or systemic treatment individualized to subsequent response [23-27].

Table 1 describes outcomes in non-metastatic IBC patients treated with modern therapy. Five-year OS rates range from 55 to $69 \%$ [6-10], with the worst survival noted in triplenegative patients (5-year OS 44\%) and the highest survival in HER2-positive patients treated with anti-HER2-targeted therapy (5-year OS 74\%) [10••]. However, LRR remains high with 3 - to 5-year cumulative rates ranging from 17 to $21 \%$ [6, $8]$. The use of tri-modality therapy is consistently an independent predictor of improved survival when compared to the use of only 1 or 2 treatment modalities [9, 28].

The involvement of multidisciplinary consultants at the time of diagnosis is crucial for optimal management, as various disciplines play a role during all stages of therapy. For example, the radiation oncologist and surgeon should examine the patient prior to the initiation of systemic therapy to ensure that all pretreatment imaging necessary for locoregional treatment planning has been performed. There should be immediate re-consult with a surgeon or radiation oncologist for exam or re-imaging if there is a concern for progression on systemic therapy, as the window for locoregional control may close quickly [24••].

\section{Presentation and Diagnosis}

The presentation of IBC is driven by rapid evolution of skin erythema and breast swelling, secondary to lymphedema caused by tumor emboli within dermal lymphatics [1]. This edema causes exaggeration of hair follicle pits, creating the classic "peau d'orange" (orange peel) appearance of the skin. In many cases, there is no discrete palpable mass on clinical breast exam, and in up to $19 \%$ of patients, there may be no clinical findings in the breast besides skin erythema [29].

The diagnosis of IBC requires a tissue confirmation of malignant cells in an underlying associated mass in the breast parenchyma or dermal tumor cells in a punch biopsy of the skin. Despite its distinct clinical behavior, a pathognomonic molecular signature for IBC has not yet been identified [30, 31]; distinguishing IBC from non-inflammatory breast cancer is based on clinical presentation. The most recent staging manual (AJCC 8th ed) requires diffuse erythema and edema of at least $1 / 3$ of the breast with rapid onset of symptoms over a 3 to 6-month time period or less [32]. The time of symptom development is the key criterion differentiating IBC from non-inflammatory locally advanced breast cancer (LABC) that may present with secondary erythema and skin involvement. While the presence of dermal lymphatic invasion on skin biopsy is usually present, it can be missed in up to $25 \%$ of patients related to skip regions within the breast, and therefore is not required for diagnosis [33, 34].

All IBC cases are defined as cT4d regardless of the presence or size of an associated breast mass, and thus, all patients with IBC are at least stage III at diagnosis. It is important to realize that $25-30 \%$ of patients will present with de novo metastatic disease. Among patients without distant disease at presentation, over $80 \%$ have clinical involvement of the regional lymph nodes $[10,35,36]$. The relative breakdown of biological subtypes differs slightly from non-IBC tumors, with a greater proportion of HER2-enriched and triplenegative tumors in IBC. In recent series, 38-39\% of IBC were ER+/HER2-, 32-35\% were HER2 enriched, and 25-28\% were triple-negative $[10,11]$.

\section{Imaging for Treatment Planning}

The optimization of locoregional treatment relies on clearly defining the extent of local, regional, and distant disease prior to the initiation of systemic therapy. The goals of initial imaging are to define the extent of disease in the breast parenchyma and skin, to evaluate for chest wall invasion, and to identify 
Table 1 Locoregional recurrence and overall survival in selected IBC studies in modern cohorts of non-metastatic IBC patients treated with trimodality therapy

\begin{tabular}{|c|c|c|c|c|c|}
\hline Study & Date & Database & $N$ median follow-up & LRR & Survival outcomes \\
\hline Romanoff et al. 2018 [6] & 2006-2016 & $\begin{array}{l}\text { Retrospective; } \\
\quad \text { single Institution }\end{array}$ & $\begin{array}{l}N=117 \\
\text { Median } \mathrm{f} / \mathrm{u} \\
3.4 \text { years }\end{array}$ & $\begin{array}{l}\text { 5-year cumulative LRR 17\% } \\
\text { 5-year isolated LRR } 4.8 \%\end{array}$ & $\begin{array}{l}\text { 5-year OS 71\% } \\
\text { 5-year DRFS 63\% }\end{array}$ \\
\hline Rosso et al. 2017 [7] & $2007-2015$ & $\begin{array}{l}\text { Prospective; } \\
\quad \text { single Institution }\end{array}$ & $\begin{array}{l}N=114 \\
\text { Median f/u } 3.6 \text { years }\end{array}$ & 5-year LRR 3.5\% & 5-year OS $69.4 \%$ \\
\hline Warren et al. 2015 [8] & 1997-2011 & $\begin{array}{l}\text { Retrospective; } \\
\text { single Institution }\end{array}$ & $\begin{array}{l}N=132 \\
\text { Median f/u } 3.3 \text { years }\end{array}$ & $\begin{array}{l}\text { 3-year cumulative LRR } \\
21.3 \%\end{array}$ & 5-year OS 58.1\% \\
\hline Van Uden et al. 2019 [9] & 2006-2015 & $\begin{array}{l}\text { Population based; } \\
\text { Netherlands Cancer Registry }\end{array}$ & $\begin{array}{l}N=1061 \\
\text { Median f/u } \\
2.4 \text { years }\end{array}$ & Not examined & 5-year OS 55.6\% \\
\hline Kuptas et al. 2019 [10] & 2010-2015 & $\begin{array}{l}\text { Population based; } \\
\text { National Cancer Database }\end{array}$ & $\begin{array}{l}N=4068^{\wedge} \\
\text { Median f/u } \\
\text { not provided }\end{array}$ & Not examined & 5 -year OS $62.2 \%$ \\
\hline
\end{tabular}

*When possible, data represents only the subgroup analysis of stage III IBC patients in whom tri-modality therapy was completed in each study. In studies where all patients did not receive tri-modality therapy, details are noted

$\wedge 19.6 \%$ of patients did not receive radiation therapy

areas of regional lymph node involvement at diagnosis, as well as to monitor response during and after PST.

Diagnostic imaging starts with bilateral mammography and ultrasound. While data supporting the routine use of breast MRI for IBC involve small, retrospective studies, it appears to be the most accurate imaging modality for detecting a primary breast lesion and defining the extent of skin involvement. For example, mammography reveals an underlying breast lesion in only $68 \%$ of patients with IBC, while MRI will detect a primary breast lesion in up to 98\% [37] (Fig. 1). For these reasons, most experts recommend MRI at diagnosis and after systemic therapy to assess treatment response [24・•].

Given the high rate of de novo metastatic disease, staging studies should be considered in all IBC cases. Current NCCN guidelines recommend staging for distant metastases to include a diagnostic CT of the chest, abdomen, and pelvis and bone scan [38]. The use of PET/CT is considered optional; however, recent data suggest that $\mathrm{PET} / \mathrm{CT}$ may be superior in evaluating for regional nodal involvement and can reveal distant metastases not seen by conventional imaging. For example, in two studies, PET/ CT detected disease not seen on conventional crosssectional imaging in up to $23 \%$ of patients and supported changes in radiotherapy planning in $18-19 \%$ [39, 40]. Prior to treatment with locoregional therapy, re-staging imaging with $\mathrm{PET} / \mathrm{CT}$ is preferred or at minimum a CT chest, abdomen, and pelvis and bone scan [24••].

Clinical photography is also recommended to document extent of skin involvement prior to initiation of systemic therapy. Photographs are a useful adjunct to conventional breast imaging in directing surgical resection and radiation treatment planning [7, 24]. Photography is especially important in cases where the surgeon or treating radiation oncologist is not able to examine the patient prior to chemotherapy.
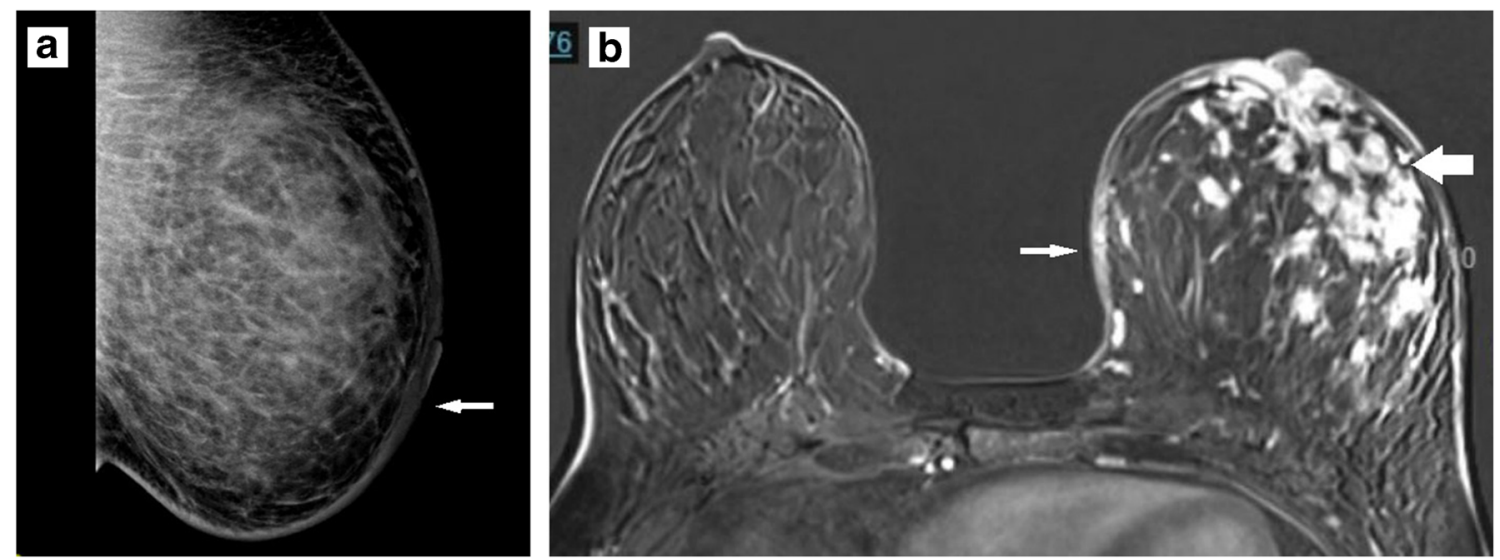

Fig. 1 Mammogram (a) and MRI (b) imaging on the same patient with inflammatory left breast cancer. Only mild skin thickening is noted on diagnostic mammogram (thin arrow), whereas MRI demonstrates extensive underlying non-mass enhancement measuring $10.9 \times 9.8 \times$ $8.4 \mathrm{~cm}$ (AP by ML by SI) throughout superior and central breast (thick arrow) with nipple retraction 


\section{Systemic Therapy for Locoregional Control}

The role of preoperative systemic therapy in locoregional management of IBC cannot be over-emphasized. Locoregional control is not simply a function of disease burden but heavily dependent on biologic subtype and response to primary systemic therapy [41]. This finding was observed in the earliest chemotherapy trials, where 5-year LRR was $11 \%$ vs $34 \%$ vs $67 \%$ in IBC patients who experienced complete, partial, or no clinical response to chemotherapy, respectively [16]. Risk of LRR and OS varies according to biologic subtype, with triple-negative IBC fairing the worst, and patients with HER2 overexpressing IBC having the lowest LRR and highest OS $[6,9,12]$.

The incidence of pathologic complete response (pCR) varies by subtype, and achieving a pCR is a significant predictor of favorable OS and freedom from recurrence $[9,10$, $12,42]$. Among 4000 non-metastatic IBC patients treated with PST from 2010 to 2015 in the NCDB, 20.1\% achieved pCR in both the breast and axilla, including $38.8 \%$ in HER2-positive, $19.1 \%$ in triple-negative, and $6.2 \%$ in HR+/HER2-negative tumors $[10 \bullet \cdot$. Patients who achieved total pCR had a 5 -year OS of $82.9 \%$, and absence of total pCR was the strongest predictor of worsened survival (HR 3.23, $p<0.001$ ). Achieving a $\mathrm{pCR}$ is associated with a low risk for LRR. In a recent series of cT4 patients treated at Memorial Sloan Kettering Cancer Center (including 117 patients with IBC), 5 -year LRR was $0 \%$ in patients with pCR compared to $15 \%$ when pCR was not achieved [6•].

Preoperative systemic therapy for IBC is tailored according to biological subtype, and largely extrapolated from studies involving non-IBC patients, given the limited number of studies specifically evaluating IBC patients. The mainstay of chemotherapy remains anthracycline- and taxane-based regimens. Improvement in outcomes with the use of intense dose-dense administration compared with conventionally scheduled chemotherapy in IBC has been studied with mixed results $[43,44]$; regardless, dose-dense regimens are commonly utilized [24••]. For HER2-positive IBC, anti-HER2directed therapies have significantly improved outcomes. In the NOAH study, a significant improvement in 5-year eventfree and overall survival was identified in a subgroup analysis of HER2-positive IBC patients who received neoadjuvant and adjuvant trastuzumab (5-year OS $74 \%$ vs $44 \%$ ) [45]. The NeoSphere study demonstrated slightly higher rates of pCR when trastuzumab was combined with pertuzumab [46], supporting dual anti-HER2-directed therapy in the neoadjuvant setting. Adjuvant systemic therapies are given according to treatment response to PST and according to biologic subtype, including endocrine therapy for estrogen receptorpositive cancer.

Inflammatory breast cancer behaves as a biologically distinct entity from other invasive breast cancers. A search for molecular aberrations and biomarkers specific to IBC to elucidate potential targeted therapies (i.e., targeting angiogenesis, tumor micro-environment, inflammation/immunity) remains an active area of research [47].

\section{Surgery}

The guideline-concordant surgical management of IBC is MRM, including clearance of level 1 and level 2 axillary lymph nodes. Breast mound reconstruction is considered primarily as a delayed procedure, occurring at least 6 months after completion of PMRT [24, 27]. Wide skin resection is performed at the time of mastectomy (including all skin involved prior to initiation of chemotherapy) to achieve negative margins. Punch biopsies of the skin (taken in clinic prior to surgery or intra-operatively) may help guide resection when the extent of skin involvement is not clear based on exam and imaging alone. In some cases, resecting the extent of skin disease will require chest wall coverage with reconstructive techniques (i.e., skin grafting or myocutaneous flap closures), with latissimus dorsi flap reconstruction being a simpler and therefore preferred method [7•]. However, in rare cases where the amount of skin necessary does not allow for primary closure of the latissimus donor site, autologous reconstruction with an abdominal donor site may need to be considered. Skin-sparing mastectomy and breast-conserving therapy are currently contraindicated given the skin involvement with IBC.

Positive surgical margins have consistently resulted in increased LRR and have been associated with lower survival [48]. In a recent series in which negative margins were achieved at surgery following tri-modality therapy, the 5year LRR rate was $3.5 \%$ [7•]. This rate is considerably lower than the $17-21 \%$ LRR reported at 3-5 years in other modern series where margin status was not provided $[6,8]$ and supports the continued use of aggressive surgical resection in patients with IBC.

Historically, IBC was considered a relative contraindication to breast reconstruction due to concerns about positive margins, a high risk of LRR, and poor survival outcomes. The NCCN recommends against immediate breast reconstruction (IBR) for the reasons previously mentioned and the necessity to proceed to PMRT without potential delay from surgical complications. However, as outcomes from tri-modality treatment improve and the benefits of undergoing reconstruction after mastectomy are increasingly recognized, patients with IBC can be considered for delayed reconstruction. Chang et al. compared 59 IBC patients who underwent mostly delayed autologous reconstruction to IBC patients who did not undergo reconstruction and demonstrated improved OS in the reconstructed group [49]. The survival advantage no doubt reflects a highly select patient population who did not 
experience early recurrence and remained eligible for delayed reconstruction (at average 18.6 months after PMRT). However, it supports the consideration of breast reconstruction in the delayed setting for patients who respond favorably to treatment.

\section{Controversies in Surgical Management}

With advances in chemotherapy and targeted therapies, rates of pCR are increasing in patients, especially in those with HER2-positive disease. A valid consideration is whether less aggressive breast surgery or less invasive axillary staging procedures can be considered in these patients who achieve an excellent response to PST. However, currently, insufficient data exists to support a tailored surgical approach for patients with IBC. Herein, we review the limited data available on the controversial use of breast conservation surgery (BCS), IBR, and sentinel lymph node biopsy (SLNB) in IBC.

\section{Safety of Breast Conservation Surgery}

Some groups are considering the use of BCS for IBC. In a consensus panel statement by the UK Inflammatory Breast Cancer Working Group, the use of BCS is considered acceptable if clear margins are obtained. However, this recommendation is given in the absence of data to support the safety of BCS in IBC [50].

Indeed, studies evaluating the use of BCS in IBC are retrospective and have small sample sizes and inherent selection biases [51-53]. Brzezinska et al. reviewed 35 IBC patients treated with BCS between 1999 and 2013, reporting a 5-year OS and locoregional recurrence-free survival of $70.3 \%$ and $87.5 \%$, respectively, with a median follow-up of 37 months [52]. Importantly, all patients presented with a localized mass, which is a rare presentation of IBC; additionally, the high OS in a pre-HER2-targeted therapy study period is incongruent with historical controls. Both findings caution extrapolation of these study results to IBC patients with classic presentation. Using the SEER database, Chen et al. evaluated 3374 women with non-metastatic IBC and found similar 5-year breast cancer-specific survival rates in patients treated with BCS compared to those treated with mastectomy [53]. A higher OS in BCS patients suggests implicit selection bias. Additionally, only $4.4 \%$ of the population received BCS in this study, and thus, without propensity score matching or competing risk analysis, this study is unlikely to represent a valid comparison of the groups based on the type of surgery.

\section{Safety of Immediate Breast Reconstruction}

A few single-institution studies and a SEER-Medicare database study have suggested that performing IBR for patients with IBC does not negatively impact survival $[49,54-56]$. Chin et al. compared 23 IBC patients who underwent mostly autologous reconstruction (14 in the IBR setting) to nonreconstructed historical controls and found no difference in disease-free or OS [54]. Another small, single institution study by Simpson et al. compared IBC patients who had undergone IBR, mostly with tissue expander-based reconstruction, to those who had no reconstruction and found no difference in OS [55]. A SEER-Medicare study performed by Patel et al. found that among 1472 patients who underwent mastectomy for IBC between 1991 and 2009, 3\% had IBR, and IBR was not associated with an increased risk of breast cancer-specific mortality, even after accounting for competing risk of death from other causes [56*0]. While supportive, these studies are limited by small numbers and an implicit selection bias.

Beyond oncologic concerns, the feasibility of IBR in IBC is limited by practical concerns. Given the diffuse skin involvement, it is typically necessary to resect a significant portion of the skin, which precludes immediate non-autologous reconstruction. Additionally, even if IBR is considered in select patients, autologous reconstruction would be preferred to replace volume and skin and to better withstand the impact of PMRT [49, 57-59]. Lastly, the aforementioned Simpson study demonstrated that IBC patients who undergo IBR experience significantly more post-operative complications than those who undergo delayed or no reconstruction; however, these complications did not significantly delay receipt of PMRT [55]. Their findings are supported by data from the non-IBC population where IBR does modestly increase time from surgery to receipt of chemotherapy but not receipt of PMRT [60 ${ }^{\circ}$ and does not appear to be clinically relevant.

\section{Considerations in Surgical Management of the Axilla}

A recent study of $3471 \mathrm{IBC}$ patients treated with tri-modality therapy in the NCDB between 2010 and 2014 found that more extensive axillary surgery $(\geq 10$ nodes removed vs $<10$ ) for cN2-3 disease was associated with improved survival. However, no survival advantage was noted with extent of axillary surgery for patients who presented with less nodal disease $(\mathrm{cN} 1$ or $\mathrm{cN} 0)[61 \bullet \cdot]$. These results, coupled with the increasing ability to achieve an axillary pCR in up to $35 \%$ of patients [61, 62], compel the consideration of less axillary surgery in a subset of IBC patients with clinically low nodal disease and/or an excellent response to PST.

Several recent prospective trials have evaluated the feasibility and safety of SLNB alone for patients undergoing surgery after PST in both $\mathrm{cN} 0$ patients and $\mathrm{cN} 1$ patients who achieve clinical axillary downstaging prior to surgery [63-65]. However, IBC patients were actively excluded from these trials, and thus, results cannot be extrapolated for use in IBC patients. 
Indeed, trials evaluating use of SLNB in IBC have been discouraging. While two prospective series have reported successful mapping in up to $75-80 \%$ of IBC patients, the staging accuracy was unacceptable with false-negative rates of $18-30 \%$ $[66,67]$. In a more recent prospective series by DeSynder et al. including 16 IBC patients undergoing dual-tracer SLN mapping, a SLN was not identified in $75 \%$ of patients [68・•]. Among the four patients who did successfully map, 3 patients had achieved $\mathrm{pCR}$ in the axilla, perhaps suggesting a future role for SLNB in a rare subset of IBC patients. However, additional studies and/or more reliable mapping techniques are necessary, and until then, ALND remains standard of care for all IBC patients regardless of treatment response.

\section{Radiotherapy}

\section{Radiotherapy Field Selection and Design}

PMRT is routinely recommended in virtually all IBC settings, given the high risk for LRR even in those patients who achieve a pCR after PST [17]. Following an MRM, adjuvant PMRT fields include the chest wall and all regional lymph node basins, including the ipsilateral axillary, infraclavicular, supraclavicular, and internal mammary lymph nodes.

The mastectomy flaps are included in their entirety, as is the scar, typically spanning from the mid-sternum to the midaxillary line. The scar may extend to the contralateral breast, for which the radiotherapy field coverage should extend as well. The chest wall volume may be more extensive depending on the amount of skin involvement, and a careful examination of the skin is important for adequate radiotherapy planning and delivery. A radiotherapy boost volume is administered to the chest wall to encompass the scar and high-risk areas, including areas with a positive margin, or residual skin/nodal involvement.

\section{Radiotherapy Dose and Schedule}

Various radiotherapy regimens have been described for the treatment of IBC, including the use of twice-daily radiotherapy [22], dose-escalated radiotherapy [22], and the use of a tissue-equivalent bolus for increasing skin coverage [69]. A common regimen used at our institution is once-daily radiotherapy using conventional fractionation (1.8-2 Gy per fraction) up to 60 Gy to the chest wall and areas with residual gross nodal disease. This dose is typically escalated to $66 \mathrm{~Gy}$, especially for younger patients, those with close or positive margins, or those with a poor response to chemotherapy [70]. While dose escalation to 66 Gy has been typically studied in the context of hyperfractionation (twice-daily radiotherapy), once-daily radiotherapy has shown similar toxicity and local control outcomes in the appropriate settings [71•]. Bolus is typically used throughout the radiotherapy treatment to maximize the dose to the skin.

\section{Preoperative Radiotherapy}

Preoperative radiotherapy is recommended when a patient remains inoperable after PST. Patients may not be candidates for surgical resection due to the extent of their residual breast/skin disease or nodal disease that may involve sensitive areas like the brachial plexus. Situations like these would benefit from disease reduction with radiotherapy prior to surgery to maximize chances for negative margins. Radiosensitizing chemotherapy, such as capecitabine, may also be administered concurrently to improve resectability [72].

\section{Re-Irradiation}

The recommendation for or against re-irradiation should be made in the context of the clinical situation, balancing the high risk for LRR in the setting of IBC with the potential morbidities of re-irradiation. Patients with a prior radiotherapy course completed over a year ago without significant toxicity from their initial treatment can be considered acceptable candidates for re-irradiation.

A similar dosing strategy is recommended, with an acceptable cumulative total dose to the chest wall up to $110 \mathrm{~Gy}$ [73]. If the regional lymph nodes had been treated previously in the initial radiotherapy course, then typically, they would not be re-treated, especially given the high risk for brachial plexopathy. However, even with previous nodal-directed irradiation, isolated gross nodal disease that remains after surgery may be targeted in a more focal manner. Re-irradiation fields are typically limited to high-risk areas in the setting of breast cancer recurrence, but in IBC, this high-risk area remains quite large and is similar to, or even larger than, a typical postmastectomy chest wall field. Hyperthermia may be utilized concurrently with radiotherapy to improve locoregional control in the setting of re-irradiation [74].

\section{Locoregional Management in De Novo Metastatic Disease}

An area of controversy in the management of breast cancer is the utilization of locoregional treatment in patients presenting with de novo distant metastatic disease, given the negative results of a randomized trial incorporating locoregional treatment or omission in this setting $[75,76]$. However, in IBC, the risk of locoregional recurrence and its associated significant morbidity 
is higher than in non-inflammatory situations, and at least $60 \%$ will have local progression with systemic therapy alone $[8,24$, 77]. Therefore, if locoregional therapy is felt to be appropriate given the clinical context (a reasonable response to chemotherapy without distant progression, a younger patient, good performance status, otherwise favorable clinical features, etc.), then the utilization of surgery and/or radiotherapy for local disease control can be considered [24••].

\section{Conclusions}

Advancements in tri-modality therapy for IBC have yielded substantial improvements in survival in recent years; however, IBC remains a significant therapeutic challenge with local failure occurring in at least $15-20 \%$ of patients at 5 years. Biologic subtype and response to PST are the most important factors predicting local control and distant recurrence. Despite increasingly promising outcomes in some patients (particularly in those with HER2-positive disease), data to support less breast/ axillary surgery and/or omission of radiotherapy in any patient group with IBC is currently lacking, and the recommendation for treatment remains the same: preoperative systemic therapy followed by modified radical mastectomy and adjuvant radiotherapy in all patients. Delayed reconstruction can be considered in patients who respond favorably to treatment and is currently preferred over immediate breast reconstruction.

As we continue to make gains in survival for patients with IBC, active research to identify patients who may benefit from de-escalation of locoregional therapies with their associated morbidities is needed.

\section{Compliance with Ethical Standards}

Conflict of Interest Maggie DiNome, John Hedge, Jennifer Baker, Carlie Thompson, and Minna Lee declare that they have no conflict of interest.

Human and Animal Rights and Informed Consent This article does not contain any studies with human or animal subjects performed by any of the authors.

Open Access This article is licensed under a Creative Commons Attribution 4.0 International License, which permits use, sharing, adaptation, distribution and reproduction in any medium or format, as long as you give appropriate credit to the original author(s) and the source, provide a link to the Creative Commons licence, and indicate if changes were made. The images or other third party material in this article are included in the article's Creative Commons licence, unless indicated otherwise in a credit line to the material. If material is not included in the article's Creative Commons licence and your intended use is not permitted by statutory regulation or exceeds the permitted use, you will need to obtain permission directly from the copyright holder. To view a copy of this licence, visit http://creativecommons.org/licenses/by/4.0/.

\section{References}

Papers of particular interest, published recently, have been highlighted as:

- Of importance

- Of major importance

1. Robertson FM, Bondy M, Yang W, Yamauchi H, Wiggins S, Kamrudin S, et al. Inflammatory breast cancer: the disease, the biology, the treatment. CA Cancer J Clin. 2010;60(6): 351-75.

2. Hance KW, Anderson WF, Devesa SS, Young HA, Levine PH. Trends in inflammatory breast carcinoma incidence and survival: the surveillance, epidemiology, and end results program at the National Cancer Institute. J Natl Cancer Inst. 2005;97(13):966-75.

3. Zucali R, Uslenghi C, Kenda R, Bonadonna G. Natural history and survival of inoperable breast cancer treated with radiotherapy and radiotherapy followed by radical mastectomy. Cancer. 1976;37(3): 1422-31.

4. Haagensen CD, Stout AP. Carcinoma of the breast. II-Criteria of Operability. Ann Surg. 1943;118(6):1032-51.

5. Treves N. The inoperability of inflammatory carcinoma of the breast. Surg Gynecol Obstet. 1959;109(2):240-2.

6. Romanoff A, Zabor EC, Petruolo O, Stempel M, El-Tamer M, Morrow M, et al. Does nonmetastatic inflammatory breast cancer have a worse prognosis than other nonmetastatic T4 cancers? Cancer. 2018;124(22):4314-21. This retrospective study from Memorial Sloan Kettering demonstrates the improved survival seen in patients with IBC in the modern era of effective trimodality therapy.

7. Rosso KJ, Tadros AB, Weiss A, Warneke CL, DeSnyder S, Kuerer $\mathrm{H}$, et al. Improved locoregional control in a contemporary cohort of nonmetastatic inflammatory breast cancer patients undergoing surgery. Ann Surg Oncol. 2017;24(10):2981-8. This prospective study from MD Anderson demonstrates a significantly low rate of local regional recurrence of $3.2 \%$ when negative surgical margins are achieved.

8. Warren LE, Guo H, Regan MM, Nakhlis F, Yeh ED, Jacene HA, et al. Inflammatory breast cancer: patterns of failure and the case for aggressive locoregional management. Ann Surg Oncol. 2015;22(8):2483-91.

9.• van Uden DJP, van Maaren MC, Bult P, Strobbe LJA, van der Hoeven JJM, Blanken-Peeters C, et al. Pathologic complete response and overall survival in breast cancer subtypes in stage III inflammatory breast cancer. Breast Cancer Res Treat. 2019;176(1): 217-26. This is a retrospective study of over 1000 patients from the Netherlands demonstrating the variable response rates seen in patients with non-metastatic inflammatory breast cancer based on biologic subtype, and that patients who achieve pCR have improved survival.

10.• Kupstas AR, Hoskin TL, Day CN, Boughey JC, Habermann EB, Hieken TJ. Biological subtype, treatment response and outcomes in inflammatory breast cancer using data from the National Cancer Database. Br J Surg. 2020;107(8):1033-41. This study of the NCDB database highlights again the importance of tailored therapy based on biologic subtype of patients with inflammatory breast cancer and demonstrates the lowest survival among patients with triple negative disease, supporting the need for improved therapy for this subgroup of patients. Patients with HER2 positive disease had the highest survival rates reflecting effecive targeted therapies. 
11. Li J, Xia Y, Wu Q, Zhu S, Chen C, Yang W, et al. Outcomes of patients with inflammatory breast cancer by hormone receptor- and HER2-defined molecular subtypes: a population-based study from the SEER program. Oncotarget. 2017;8(30):49370-9.

12. Liu J, Chen K, Jiang W, Mao K, Li S, Kim MJ, et al. Chemotherapy response and survival of inflammatory breast cancer by hormone receptor- and HER2-defined molecular subtypes approximation: an analysis from the National Cancer Database. J Cancer Res Clin Oncol. 2017;143(1):161-8.

13. Fletcher GH, Montague ED. Radical irradiation of advanced breast cancer. Am J Roentgenol Radium Therapy, Nucl Med. 1965;93: 573-84.

14. Bozzetti F, Saccozzi R, De Lena M, Salvadori B. Inflammatory cancer of the breast: analysis of 114 cases. J Surg Oncol. 1981;18(4):355-61.

15. Rouesse J, Friedman S, Sarrazin D, Mouriesse H, Le Chevalier T, Arriagada R, et al. Primary chemotherapy in the treatment of inflammatory breast carcinoma: a study of 230 cases from the Institut Gustave-Roussy. J Clin Oncol. 1986;4(12):1765-71.

16. Thoms WW Jr, McNeese MD, Fletcher GH, Buzdar AU, Singletary SE, Oswald MJ. Multimodal treatment for inflammatory breast cancer. Int J Radiat Oncol Biol Phys. 1989;17(4):739-45.

17. Cristofanilli M, Valero V, Buzdar AU, Kau SW, Broglio KR, Gonzalez-Angulo AM, et al. Inflammatory breast cancer (IBC) and patterns of recurrence: understanding the biology of a unique disease. Cancer. 2007;110(7):1436-44.

18. Perez CA, Fields JN, Fracasso PM, Philpott G, Soares RL Jr, Taylor ME, et al. Management of locally advanced carcinoma of the breast. II Inflammatory carcinoma. Cancer. 1994;74(1 Suppl):466-76.

19. Panades M, Olivotto IA, Speers CH, Shenkier T, Olivotto TA, Weir $\mathrm{L}$, et al. Evolving treatment strategies for inflammatory breast cancer: a population-based survival analysis. J Clin Oncol. 2005;23(9): 1941-50.

20. Fleming RY, Asmar L, Buzdar AU, McNeese MD, Ames FC, Ross MI, et al. Effectiveness of mastectomy by response to induction chemotherapy for control in inflammatory breast carcinoma. Ann Surg Oncol. 1997;4(6):452-61.

21. Liauw SL, Benda RK, Morris CG, Mendenhall NP. Inflammatory breast carcinoma: outcomes with trimodality therapy for nonmetastatic disease. Cancer. 2004;100(5):920-8.

22. Liao Z, Strom EA, Buzdar AU, Singletary SE, Hunt K, Allen PK, et al. Locoregional irradiation for inflammatory breast cancer: effectiveness of dose escalation in decreasing recurrence. Int J Radiat Oncol Biol Phys. 2000;47(5):1191-200.

23. Lin HY, Bedrosian I, Babiera GV, Shaitelman SF, Kuerer HM, Woodward WA, et al. Using the National Cancer Data Base for quality evaluation to assess adherence to treatment guidelines for nonmetastatic inflammatory breast cancer. Cancer. 2017;123(14): 2618-25.

24.• Ueno NT, Espinosa Fernandez JR, Cristofanilli M, Overmoyer B, Rea D, Berdichevski F, et al. International consensus on the clinical management of inflammatory breast cancer from the Morgan Welch inflammatory breast cancer research program 10th anniversary conference. J Cancer. 2018;9(8):1437-47. This represents the most current international consensus guidelines for the clinical management of inflammatory breast cancer.

25. Devi GR, Hough H, Barrett N, Cristofanilli M, Overmoyer B, Spector N, et al. Perspectives on inflammatory breast cancer (IBC) research, clinical management and community engagement from the Duke IBC consortium. J Cancer. 2019;10(15):3344-51.

26. Dawood S, Merajver SD, Viens P, Vermeulen PB, Swain SM, Buchholz TA, et al. International expert panel on inflammatory breast cancer: consensus statement for standardized diagnosis and treatment. Ann Oncol. 2011;22(3):515-23.

27. NCCN Clinical practice guidelines in oncology: breast cancer.; Version 4.2020.
28. Rueth NM, Lin HY, Bedrosian I, Shaitelman SF, Ueno NT, Shen $\mathrm{Y}$, et al. Underuse of trimodality treatment affects survival for patients with inflammatory breast cancer: an analysis of treatment and survival trends from the National Cancer Database. J Clin Oncol. 2014;32(19):2018-24.

29. Yang WT, Le-Petross HT, Macapinlac H, Carkaci S, GonzalezAngulo AM, Dawood S, et al. Inflammatory breast cancer: PET/ CT, MRI, mammography, and sonography findings. Breast Cancer Res Treat. 2008;109(3):417-26.

30. Van Laere SJ, Ueno NT, Finetti P, Vermeulen P, Lucci A, Robertson FM, et al. Uncovering the molecular secrets of inflammatory breast cancer biology: an integrated analysis of three distinct affymetrix gene expression datasets. Clin Cancer Res. 2013;19(17):4685-96.

31. Ross JS, Ali SM, Wang K, Khaira D, Palma NA, Chmielecki J, et al. Comprehensive genomic profiling of inflammatory breast cancer cases reveals a high frequency of clinically relevant genomic alterations. Breast Cancer Res Treat. 2015;154(1):155-62.

32. AJCC Cancer Staging Manual. 8 ed: springer international publishing; 2017.

33. Bonnier P, Charpin C, Lejeune C, Romain S, Tubiana N, Beedassy $\mathrm{B}$, et al. Inflammatory carcinomas of the breast: a clinical, pathological, or a clinical and pathological definition? Int $\mathrm{J}$ Cancer. 1995;62(4):382-5.

34. Resetkova E. Pathologic aspects of inflammatory breast carcinoma: part 1. Histomorphology and differential diagnosis. Semin Oncol. 2008;35(1):25-32.

35. Walshe JM, Swain SM. Clinical aspects of inflammatory breast cancer. Breast Dis. 2005;22:35-44.

36. Matro JM, Li T, Cristofanilli M, Hughes ME, Ottesen RA, Weeks $\mathrm{JC}$, et al. Inflammatory breast cancer management in the national comprehensive cancer network: the disease, recurrence pattern, and outcome. Clin Breast Cancer. 2015;15(1):1-7.

37. Le-Petross HT, Cristofanilli M, Carkaci S, Krishnamurthy S, Jackson EF, Harrell RK, et al. MRI features of inflammatory breast cancer. AJR Am J Roentgenol. 2011;197(4):W769-76.

38. Gradishar WJ, Anderson BO, Abraham J, Aft R, Agnese D, Allison $\mathrm{KH}$, et al. NCCN clinical practice guidelines in oncology. J Natl Compr Cancer Netw. 2020;18(4):452-78.

39. Jacene HA, DiPiro PJ, Bellon J, Hu J, Cheng SC, Warren L, et al. Discrepancy between FDG-PET/CT and contrast-enhanced CT in the staging of patients with inflammatory breast cancer: implications for treatment planning. Breast Cancer Res Treat. 2020;181(2): 383-90. This recent study from the Dana Farber Cancer Insitute supports that FDG-PET/CT should be considered as the imaging modality of choice for initial staging of IBC to optimize treatment planning.

40. Walker GV, Niikura N, Yang W, Rohren E, Valero V, Woodward WA, et al. Pretreatment staging positron emission tomography/ computed tomography in patients with inflammatory breast cancer influences radiation treatment field designs. Int J Radiat Oncol Biol Phys. 2012;83(5):1381-6.

41. Morrow M. Rethinking the local therapy of breast cancer: integration of biology and anatomy. Ann Surg Oncol. 2015;22(10):3168-73.

42. Nakhlis F, Regan MM, Warren LE, Bellon JR, Hirshfield-Bartek J, Duggan MM, et al. The impact of residual disease after preoperative systemic therapy on clinical outcomes in patients with inflammatory breast cancer. Ann Surg Oncol. 2017;24(9):2563-9.

43. Ellis GK, Barlow WE, Gralow JR, Hortobagyi GN, Russell CA, Royce ME, et al. Phase III comparison of standard doxorubicin and cyclophosphamide versus weekly doxorubicin and daily oral cyclophosphamide plus granulocyte colony-stimulating factor as neoadjuvant therapy for inflammatory and locally advanced breast cancer: SWOG 0012. J Clin Oncol. 2011;29(8):1014-21.

44. Untch M, Mobus V, Kuhn W, Muck BR, Thomssen C, Bauerfeind I, et al. Intensive dose-dense compared with conventionally 
scheduled preoperative chemotherapy for high-risk primary breast cancer. J Clin Oncol. 2009;27(18):2938-45.

45. Gianni L, Eiermann W, Semiglazov V, Lluch A, Tjulandin S, Zambetti $\mathrm{M}$, et al. Neoadjuvant and adjuvant trastuzumab in patients with HER2-positive locally advanced breast cancer (NOAH): follow-up of a randomised controlled superiority trial with a parallel HER2-negative cohort. Lancet Oncol. 2014;15(6):640-7.

46. Gianni L, Pienkowski T, Im YH, Tseng LM, Liu MC, Lluch A, et al. 5-year analysis of neoadjuvant pertuzumab and trastuzumab in patients with locally advanced, inflammatory, or early-stage HER2positive breast cancer (NeoSphere): a multicentre, open-label, phase 2 randomised trial. Lancet Oncol. 2016;17(6):791-800.

47. Woodward WA, Cristofanilli M, Merajver SD, Van Laere S, Pusztai L, Bertucci F, et al. Scientific summary from the Morgan Welch MD Anderson Cancer Center inflammatory breast cancer (IBC) program 10(th) anniversary conference. J Cancer. 2017;8(17):3607-14.

48. Curcio LD, Rupp E, Williams WL, Chu DZ, Clarke K, OdomMaryon T, et al. Beyond palliative mastectomy in inflammatory breast cancer-a reassessment of margin status. Ann Surg Oncol. 1999;6(3):249-54.

49. Chang EI, Chang EI, Ito R, Zhang H, Nguyen AT, Skoracki RJ, et al. Challenging a traditional paradigm: 12-year experience with autologous free flap breast reconstruction for inflammatory breast cancer. Plast Reconstr Surg. 2015;135(2):262e-9e.

50. Rea D, Francis A, Hanby AM, Speirs V, Rakha E, Shaaban A, et al. Inflammatory breast cancer: time to standardise diagnosis assessment and management, and for the joining of forces to facilitate effective research. Br J Cancer. 2015;112(9):1613-5.

51. Bonev V, Evangelista M, Chen JH, Su MY, Lane K, Mehta R, et al. Long-term follow-up of breast-conserving therapy in patients with inflammatory breast cancer treated with neoadjuvant chemotherapy. Am Surg. 2014;80(10):940-3.

52. Brzezinska M, Williams LJ, Thomas J, Michael DJ. Outcomes of patients with inflammatory breast cancer treated by breastconserving surgery. Breast Cancer Res Treat. 2016;160(3):387-91.

53. Chen H, Wu K, Wang M, Wang F, Zhang M, Zhang P. A standard mastectomy should not be the only recommended breast surgical treatment for non-metastatic inflammatory breast cancer: a large population-based study in the surveillance, epidemiology, and end results database 18. Breast. 2017;35:48-54.

54. Chin PL, Andersen JS, Somlo G, Chu DZ, Schwarz RE, Ellenhorn JD. Esthetic reconstruction after mastectomy for inflammatory breast cancer: is it worthwhile? J Am Coll Surg. 2000;190(3): 304-9.

55. Simpson AB, McCray D, Wengler C, Crowe JP, Djohan R, Tendulkar R, et al. Immediate reconstruction in inflammatory breast cancer: challenging current care. Ann Surg Oncol. 2016;23(Suppl 5):642-8.

56.• Patel SA, Ng M, Nardello SM, Ruth K, Bleicher RJ. Immediate breast reconstruction for women having inflammatory breast cancer in the United States. Cancer Med. 2018;7(7):2887-902. This study from Fox Chase based on the SEER registry demonstrates that immediate reconstruction does not lead to increased mortality for patients with inflammatory breast cancer.

57. Chen TA, Momeni A, Lee GK. Clinical outcomes in breast cancer expander-implant reconstructive patients with radiation therapy. J Plast Reconstr Aesthet Surg. 2016;69(1):14-22.

58. El-Sabawi B, Sosin M, Carey JN, Nahabedian MY, Patel KM. Breast reconstruction and adjuvant therapy: a systematic review of surgical outcomes. J Surg Oncol. 2015;112(5):458-64.

59. Agarwal S, Kidwell KM, Farberg A, Kozlow JH, Chung KC, Momoh AO. Immediate reconstruction of the radiated breast: recent trends contrary to traditional standards. Ann Surg Oncol. 2015;22(8):2551-9.
60. Baek SH, Bae SJ, Yoon CI, Park SE, Cha CH, Ahn SG, et al. Immediate breast reconstruction does not have a clinically significant impact on adjuvant treatment delay and subsequent survival outcomes. J Breast Cancer. 2019;22(1):109-19. This retrospective study suggests that although immediate reconstruction does result in significant delay to adjuvant therapies, this delay is not clinically significant.

61.• Fayanju OM, Ren Y, Greenup RA, Plichta JK, Rosenberger LH, Force $\mathrm{J}$, et al. Extent of axillary surgery in inflammatory breast cancer: a survival analysis of 3500 patients. Breast Cancer Res Treat. 2020;180(1):207-17. This is a significant study because it is assessing whether a subgroup of patients with IBC exists who can potentially be spared axillary dissection based on clinical nodal status. Patients with $\mathrm{cN2} / \mathrm{N} 3$ disease appear to benefit from more aggressive axillary dissection $(\geq 10$ nodes removed) in terms of improved survival but this same survival advantage is not seen in patients with $\mathrm{cNO}$ disease.

62. Imeokparia FO, Hughes TM, Dossett LA, Jeruss JS, Chang AE, Sabel MS. Axillary pathologic complete response in inflammatory breast cancer patients: implications for SLNB? Ann Surg Oncol. 2019;26(10):3374-9.

63. Kuehn T, Bauerfeind I, Fehm T, Fleige B, Hausschild M, Helms G, et al. Sentinel-lymph-node biopsy in patients with breast cancer before and after neoadjuvant chemotherapy (SENTINA): a prospective, multicentre cohort study. Lancet Oncol. 2013;14(7): 609-18.

64. Hunt KK, Yi M, Mittendorf EA, Guerrero C, Babiera GV, Bedrosian I, et al. Sentinel lymph node surgery after neoadjuvant chemotherapy is accurate and reduces the need for axillary dissection in breast cancer patients. Ann Surg. 2009;250(4):558-66.

65. Boughey JC, Suman VJ, Mittendorf EA, Ahrendt GM, Wilke LG, Taback B, et al. Sentinel lymph node surgery after neoadjuvant chemotherapy in patients with node-positive breast cancer: the ACOSOG Z1071 (Alliance) clinical trial. JAMA. 2013;310(14): 1455-61.

66. Stearns V, Ewing CA, Slack R, Penannen MF, Hayes DF, Tsangaris TN. Sentinel lymphadenectomy after neoadjuvant chemotherapy for breast cancer may reliably represent the axilla except for inflammatory breast cancer. Ann Surg Oncol. 2002;9(3):23542.

67. Hidar S, Bibi M, Gharbi O, Tebra S, Trabelsi A, Korbi S, et al. Sentinel lymph node biopsy after neoadjuvant chemotherapy in inflammatory breast cancer. Int J Surg. 2009;7(3):272-5.

68.• DeSnyder SM, Mittendorf EA, Le-Petross C, Krishnamurthy S, Whitman GJ, Ueno NT, et al. Prospective feasibility trial of sentinel lymph node biopsy in the setting of inflammatory breast cancer. Clin Breast Cancer. 2018;18(1):e73-e7. This is a very significant prospective study from MD Anderson demonstrating the low rate of successful sentinel lymph node mapping in patients treated with NAC, supporting that axillary lymph node dissection currently remains the standard of care for patients with IBC regardless of clinical response.

69. Brown L, Harmsen W, Blanchard M, Goetz M, Jakub J, Mutter R, et al. Once-daily radiation therapy for inflammatory breast cancer. Int J Radiat Oncol Biol Phys. 2014;89(5):997-1003.

70. Bristol IJ, Woodward WA, Strom EA, Cristofanilli M, Domain D, Singletary SE, et al. Locoregional treatment outcomes after multimodality management of inflammatory breast cancer. Int J Radiat Oncol Biol Phys. 2008;72(2):474-84.

71. Stecklein SR, Rosso KJ, Nuanjing J, Tadros AB, Weiss A, DeSnyder SM, et al. Excellent locoregional control in inflammatory breast cancer with a personalized radiation therapy approach. Pract Radiat Oncol. 2019;9(6):402-9. This is a recent study from MD Anderson based on a prospectively maintained database of patients with IBC that demonstrates that a personalized 
radiation therapy approach of daily versus BID treatment results in excellent locoregional control.

72. Woodward WA, Fang P, Arriaga L, Gao H, Cohen EN, Reuben $\mathrm{JM}$, et al. A phase 2 study of capecitabine and concomitant radiation in women with advanced breast cancer. Int J Radiat Oncol Biol Phys. 2017;99(4):777-83.

73. Harms W, Budach W, Dunst J, Feyer P, Fietkau R, Haase W, et al. DEGRO practical guidelines for radiotherapy of breast cancer VI: therapy of locoregional breast cancer recurrences. Strahlentherapie und Onkologie : Organ der Deutschen Rontgengesellschaft [et al]. 2016;192(4):199-208.

74. Datta NR, Puric E, Klingbiel D, Gomez S, Bodis S. Hyperthermia and radiation therapy in locoregional recurrent breast cancers: a systematic review and meta-analysis. Int J Radiat Oncol Biol Phys. 2016;94(5):1073-87.

75. Badwe R, Hawaldar R, Nair N, Kaushik R, Parmar V, Siddique S, et al. Locoregional treatment versus no treatment of the primary tumour in metastatic breast cancer: an open-label randomised controlled trial. Lancet Oncol. 2015;16(13):1380-8.

76. Khan SA, Zhao F, Solin LJ, Goldstein LJ, Cella D, Basik M et al. A randomized phase III trial of systemic therapy plus early local therapy versus systemic therapy alone in women with de novo stage IV breast cancer: a trial of the ECOGACRIN Research Group (E2108). J Clin Oncol. 2020;38:18_suppl, LBA2-LBA2.

77. Akay CL, Ueno NT, Chisholm GB, Hortobagyi GN, Woodward WA, Alvarez RH, et al. Primary tumor resection as a component of multimodality treatment may improve local control and survival in patients with stage IV inflammatory breast cancer. Cancer. 2014;120(9):1319-28.

Publisher's Note Springer Nature remains neutral with regard to jurisdictional claims in published maps and institutional affiliations. 